\section{Reducing greenhouse gases}

SIR - Victor and Salt ${ }^{1}$ argue that the goals of the United Nations Framework Convention on Climate Change can be advanced most effectively by focusing on improved reporting and review procedures rather than on adopting legally binding targets and timetables for reducing greenhouse gas emissions. This assertion appears to be based on the very disappointing nature of most national plans developed in response to the 'soft' target currently in the convention, which requires industrialized countries to adopt policies and measures "aimed" at returning greenhouse gas emissions to 1990 levels by 2000 . The limited success of the soft-target approach, however, indicates that legally binding emission-reduction targets and timetables are needed, not that targets in general are ineffective. The remarkable success of the Montreal Protocol on Substances that Deplete the Ozone Layer clearly demonstrates that internationally agreed emission reduction requirements can work.

It is certainly true that national efforts to reduce greenhouse gas emissions have so far been extremely deficient, as documented in a recent review conducted by nongovernmental organizations in 20 OECD and 10 Central and Eastern European countries ${ }^{2,3}$. This review reveals that many countries have failed to adopt politically difficult measures, at least in part because they expect that other countries will also fail to meet their commitments. Sole reliance on the report and review procedure recommended by Victor and Salt thus has the potential to lead to a race to the bottom, rather than the hoped-for positive reinforcement.

Adoption of political targets in the absence of clearly defined plans for achieving them does indeed create a serious risk of non-compliance. The solution proposed by most OECD governments at the preparatory meeting for the Conference of Parties on 9 February is to negotiate a protocol that includes both targets and agreed measures (see, for example, Statement of France on behalf of the European Union Intergovernmental Negotiating Committee for a Framework Convention on Climate Change (11th Session), New York, 8 February 1995). This approach gives each party assurances that it will not put itself at a competitive disadvantage by acting unilaterally. Reaching final agreement on such a protocol will undoubtedly be difficult, but there is no alternative if the problem of global climate change is to be seriously addressed.

\section{Daniel A. Lashof}

Natural Resources Defense Council, 1350 New York Avenue, NW,

Washington, DC 20005, USA
SIR - The countries negotiating targets during forthcoming meetings of the Conference of the Parties for the Framework Climate Convention should consider a broader range of ideas on commitments than have circulated in the three years since the convention's signing in Rio de Janeiro in 1992. Contrary to the argument of Victor and Salt ${ }^{1}$, targets of some kind are necessary to drive change, as indicated by decades of experience with environmental problems both before and after targets and standard-setting in domestic, bilateral and international environmental agreements ${ }^{4}$. However, as Victor and Salt mention in passing, countries are not likely to meet any numerical emissions target precisely.

A review of historical $\mathrm{CO}_{2}$ data reveals that annual emissions from energy consumption fluctuated wildly in many Annex I (industrialized) countries during the 1980s. Of 23 industrialized countries considered, about one third experienced an emissions increase of at least 10 per cent from one year to the next during the period 1980-90; emissions in all these countries differed by more than 5 per cent from a longer-term national trend in at least one year during this interval ${ }^{5}$. Given that $\mathrm{CO}_{2}$ emissions are the product of many confounding forces, emissions will vary widely until greenhouse gases become as marginal (or as sectorally concentrated) as other things that are given targets in international agreements such as halocarbons, Mark 12A warheads, or even sulphur dioxide. It is the nature of democracy that national economies are inherently unpredictable, but even alternative systems cannot plan emissions exactly, as the rolling $\mathrm{CO}_{2}$ emissions time series of formerly centrally planned countries indicate. Instead of setting only one national emissions target for one year, for example, $\mathrm{CO}_{2}$ stabilization in 2000 at 1990 levels, parties could adopt an alternative target averaged over an interval.

A stabilization target could be accompanied by a population-adjusted average carbon intensity improvement target. As they are easier to achieve. goals for annual average change in $\mathrm{CO}_{2} /(\mathrm{GNP} /$ capita) should be more stringent than national greenhouse gas emissions targets. For example, if countries fail to meet an emissions stabilization target in 2(0)(0), but can show that they improved their per capita carbon intensity by an average of 2 per cent each year during $199(1) 2(0)(0)$, they may still be judged to be in compliance. Other countries may aim for and reach an emissions target, but given the uncertainty in projecting economic swings. all but the least carbon-intensive countries may well decide to aim for the intensity target as backup. Historical data indicate that carbon/output relationships show greater linearity than national carbon trends ${ }^{5,6}$. An intensity target would help to focus planning on innovations in efficiency and conservation rather than relving on the 'recession' programme implicit in many nation's greenhouse gas projections. Targets based on average annual change might also lessen the temptation to inflate the baseline emissions estimates, a tactic evident in several of the 1990 fossil fuelrelated emissions inventories submitted last year.

Finally, average annual targets - applied to either $\mathrm{CO}_{2}$ intensity or $\mathrm{CO}_{2}$ emissions changes - will help to steer climate programmes and their review towards the longer term rather than relying on the uncertain outcome of one arbitrary target year.

\section{S. E. Subak}

CSERGE,

University of East Anglia,

Norwich NR4 7TJ, UK

1. Victor, D. G. \& Salt, J. E. Nature 373. 280282 (1995).

2. USClimate Action Network and Clımate Network Europe. Independent NGO Evaluations of National Plans for Climate Change Mitigation: OECD Countries (Climate Network Europe, Bruxelles, 1995)

3. Climate Action Network - Central and Eastern Europe and Climate Network Europe, Independent NGO Evaluations of National Plans for Climate Change Mitigation: Central and Eastern Europe (Climate Network Europe. Bruxelles. 1995).

4. OECD Environmental Performance Reviews (Organization for Economic Co-operation and Development. Parıs. 1994).

5. Marland, G., Andres, R. J. \& Boden. T A Global. Regional and National $\mathrm{CO}_{2}$ Emissions (Oak Rıgge National Laboratory, Oak Ridge. 1993)

6. International Financial Statistics Yearbook (Internationai Monetary Fund, Washington, 1994)

\section{When life begins}

SIR - There still seems to be some misunderstanding about when the new life begins $^{1-3}$. This clearly must be when the egg is activated to carry on with its development to completion. Without activation it stays as it is, until it eventually dies. And although an egg is normally activated when or soon after it is fertilized, that is not always so. For example, frogs' eggs can be activated to develop parthenogenetically, with no sperm involved at all.

But whether or not this is of any ethical or theological significance. Godfrey is wrong in saying ${ }^{4}$ that "Activation, though rapid, is not instantaneous". It is true that the processes ending with activation may take seconds, or possibly minutes, from start to finish, but the actual activation itself is indeed instantaneous in the sense that the egg either is activated or it is not, and it cannot be half activated.

\section{B. Goodhart}

Gonville \& Caius College,

Cambridge, UK

\footnotetext{
1. Jones, D.A. \& Haynie, D.T. Nature 373. 652 (1995)

2. Herranz, G. Nature 373, 652 (1995)

3. Jarmulowicz, M. Nature 373, 652 (1995)

4. Godfrey, J. Nature 373, 100 (1995).
} 